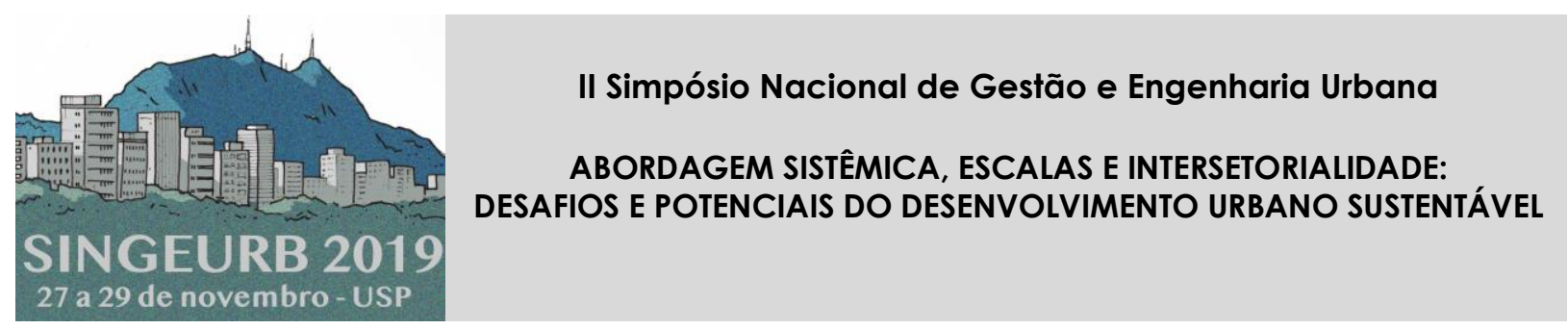

\title{
A extinção do Ministério das Cidades e seu impacto na revisão dos Planos Diretores Participativos ${ }^{1}$
}

\section{The Ministry of Cities extinction and its impact on the participative master plans review}

\author{
Medeiros, Sandra Batista1; Gonçalves, Luciana Márcia2; \\ ' Universidade Federal de São Carlos (UFSCar), São Carlos-SP, Brasil, \\ sandrabmed@gmail.com \\ 2 Universidade Federal de São Carlos (UFSCar), arq.Iuciana.ufscar@gmail.com
}

\begin{abstract}
RESUMO
A recente extinção do Ministério das Cidades traz questionamentos sobre as perspectivas futuras da política urbana no Brasil. Este trabalho tem por objetivo expor reflexões a respeito do planejamento urbano das cidades brasileiras cujos planos diretores participativos estão em fase de revisão e as consequências da extinção desse Ministério para a garantia de uma gestão municipal democrática. Esta pesquisa compõe o início de um projeto de mestrado em andamento no Programa de Pós-Graduação em Engenharia Urbana da Universidade Federal de São Carlos. Para fins metodológicos, realizou-se consulta à legislação específica e revisão bibliográfica com auxílio de livros, artigos científicos, teses, dissertações nas áreas de plano diretor participativo, estatuto da cidade, ministério das cidades, planejamento urbano, governança urbana, gestão democrática e participativa. Assim, com uma breve exposição cronológica dos principais fatos e instituições criados no Brasil desde a Constituição de 1988, aponta-se um atual cenário nacional estagnado ou retrógrado dos avanços alcançados sobre a reforma urbana brasileira nas últimas décadas. Após quase vinte anos de vigência do Estatuto da Cidade, ressalta-se a relevância da análise do planos diretores e suas respectivas revisões, entretanto, vemos que a estrutura hierárquica da política urbana integrada está comprometida com a extinção do Ministério das Cidades.
\end{abstract}

Palavras-chave: Ministério das cidades, Plano Diretor participativo, Estatuto da Cidade, Governança urbana.

\begin{abstract}
The recent extinction of the Ministry of Cities raises questions about the prospects of urban politics in Brazil. This work aims to present thoughts on the urban planning of Brazilian cities whose participative master plans are under review and the consequences of the extinction of this Ministry for the guarantee of democratic municipal management. This research composes the beginning of a project in progress in the Postgraduate Program in Urban Engineering of the Universidade Federal de São Carlos. For methodological purposes, specific legislation and
\end{abstract}

\footnotetext{
1 MEDEIROS, Sandra Batista; GONÇALVES, Luciana Márcia; A extinção do Ministério das Cidades e seu impacto na revisão dos Planos Diretores Participativos. In: II SIMPÓSIO NACIONAL DE GESTÃO E ENGENHARIA URBANA: SINGEURB, 2019, São Paulo. Anais... Porto Alegre: ANTAC, 2019.
} 
literature review were carried out with books, scientific articles, theses, dissertations in the areas of participative master plan, city statute, ministry of cities, urban planning, urban governance, democratic and participatory management. Thus, with a brief chronological exposition of the main facts and institutions created in Brazil since the 1988 Constitution, a current national scenario is stagnated or retrograde of the progress achieved on Brazilian urban reform in the last decades. After almost twenty years of validity of the City Statute, we highlight the relevance of the analysis of the master plans and their respective revisions, however, we see that the hierarchical structure of integrated urban policy is committed to the extinction of the Ministry of Cities.

Keywords: Ministry of Cities, Participative Master Plan, City Statute, Urban Governance.

\section{INTRODUÇÃO}

O atual cenário da política urbana brasileira apresenta um propício período para discussão e reflexão. Após um progressivo processo de conquistas legislativas desde a redemocratização do país na década de 1980, que resultou na Constituição Democrática Federativa em 1988 e a aprovação do Estatuto da Cidade em 2001, o corrente ano de 2019 iniciou-se com a extinção do Ministério das Cidades para se anexar ao Ministério do Desenvolvimento Regional (BRASIL, 2019). Tal medida coloca em risco os avanços alcançados quanto a redução das desigualdades sociais pertinente às questões urbana e habitacional.

Este artigo trata da temática do planejamento urbano das cidades brasileiras cujos planos diretores participativos estão em fase de revisão e as consequências da extinção do Ministério das Cidades para a garantia de uma gestão municipal democrática. Esta pesquisa faz parte de projeto de mestrado em andamento no Programa de Pós-Graduação em Engenharia Urbana da Universidade Federal de São Carlos, cujo objetivo geral é analisar as revisões ocorridas nos planos diretores no período entre 2005 e 2016 das cidades médias do interior de São Paulo, Araraquara e São Carlos, com ênfase no impacto desse instrumento de planejamento na gestão territorial desses municípios.

\section{METODOLOGIA}

Quanto aos instrumentos de investigação, trata-se de um estudo interdisciplinar de caráter transversal, exploratório e descritivo, de metodologia qualitativa, na qual realizou-se consulta à legislação específica, levantamento bibliográfico por meio de livros, artigos científicos, teses, dissertações nas áreas de plano diretor participativo, estatuto da cidade, ministério das cidades, planejamento urbano, governança urbana, gestão democrática e participativa.

\section{OS PLANOS DIRETORES NO CONTEXTO DO MINISTÉRIO DAS CIDADES}

Iniciativas populares de movimentos sociais desde o Seminário de Habitação e Reforma Urbana em 1963 e a articulação do Movimento Nacional da Reforma Urbana (MNRU) conduziram o debate para a formulação da Nova Constituição Brasileira em 1988 (BONDUKI, 2018) (DE GRAZIA; RODRIGUES, 2003).

A Constituição Federal de 1988 representou um marco legislativo histórico no Brasil por tratar da política urbana e o processo de implementação do plano diretor, anteriormente facultativo (CARDOSO, 1997).

Esta luta, expressa em articulações de entidades dos movimentos populares, sindicatos, profissionais, organizações não-governamentais, instituições acadêmicas e técnicos dos poderes públicos, das regiões metropolitanas principalmente, levou à conquista de capítulos urbanos nas Constituições Estaduais e Leis Orgânicas, coerentes com a Constituição Federal (DE GRAZIA; RODRIGUES, 2003, p.14)

A Carta Magna determinou a elaboração de Constituições Estaduais num prazo máximo de um ano. Nesse período, também se delegou aos municípios a discussão e votação da Lei 
Orgânica pelas câmaras municipais (BELLON, 2016), caminho pelo qual se direcionou a legislação para os planos diretores municipais.

Para regulamentar os artigos 182 e 183 da Constituição Federal, que tratam sobre política urbana, o governo federal instituiu o Estatuto da Cidade, após onze anos de tramitação no congresso (BONDUKI, 2018), por meio da lei n ${ }^{\circ} 10.257$ de 10 de julho de 2001, estabelecendo "normas de ordem pública e interesse social que regulam o uso da propriedade urbana em prol do bem coletivo, da segurança e do bem-estar dos cidadãos, bem como do equilíbrio ambiental" (BRASIL, 2001, art. 1\%).

A principal instrução do Estatuto da Cidade foi a obrigatoriedade de elaboração de um Plano Diretor para municípios com mais de 20 mil habitantes, integrantes de regiões metropolitanas e aglomerações urbanas. O Estatuto, no $\S 3^{\circ}$ do seu artigo 40, determina que, pelo menos, a cada dez anos, os planos devem ser revistos, conforme determinado na lei instituída pelo município.

O Plano Diretor é definido como um instrumento básico da política de desenvolvimento e de expansão urbana cujos objetivos são fixados nos âmbitos políticos, administrativos, sociais e físico-ambientais. Sua importância é pautada no direcionamento da gestão municipal quanto ao uso do solo, zoneamento e à implantação de serviços e infraestrutura para a melhoria da qualidade de vida da população, além de promover a redução às desigualdades sociais. Outra característica relevante do plano diretor é a participação popular, na qual resulta numa lei aprovada pela câmara de vereadores com a contribuição da sociedade civil, a gestão municipal e a equipe técnica (BRASIL, 2001).

\begin{abstract}
Desde a extinção do BNH, a incumbência de implementar política urbana passou por vários ministérios e secretarias, que produziram programas fragmentados e descontínuos, demonstrando a ausência de informações sistemáticas, de quadros técnicos qualificados e de estratégias para enfrentar os problemas urbanos (DE GRAZIA; RODRIGUES, 2003, p. 17).
\end{abstract}

Assim, em $1^{\circ}$ de janeiro de 2003, é criado o Ministério das Cidades (MC), conquista de vários movimentos interessados pela reforma urbana brasileira desde a década de 1980 (SUTTI, 2018), na qual "[...] caberia, especialmente, uma ação planejadora, normativa e articuladora, a elaboração de planos nacionais e a implantação de um sistema permanente de dados sobre as questões urbana e habitacional." (DE GRAZIA; RODRIGUES, 2003, p. 17).

O MC possuía uma estrutura organizacional em secretarias integradas cujo objetivo era auxiliar e capacitar os municípios além de registrar as experiências da gestão. Foram elas: Secretaria Nacional de Habitação, Secretaria Nacional de Saneamento Ambiental, Secretaria Nacional de Transporte e Mobilidade e Secretaria Nacional de Programas Urbanos. (BRASIL, 2003) (MARICATO, 2003).

Além dos planos diretores participativos, o Plano Nacional de Habitação (PNH), criado em 2004, buscou a implementação de instrumentos para a retomada do planejamento do setor habitacional pela iniciativa do governo federal. Vale destacar também o Programa Minha Casa Minha Vida (PMCMV) proposto no ano de 2009 para os setores internos da construção civil e promoção imobiliária estimulado pelo receio da crise internacional ocorrida em 2008 (SUTTI, 2018).

Após o conturbado período político desde o impeachment em 2016, e apesar do enfraquecimento do PMCMV no final do mandato presidencial, a recente extinção do Ministério das Cidades, por meio do decreto n 9.666, de 2 de janeiro de 2019, traz em risco as discussões e os instrumentos de gestão alcançados na temática da política urbana integrada, sobretudo nos últimos vinte anos (BRASIL, 2019).

\title{
4 RESULTADOS E DISCUSSÕES
}

Bonduki (2018) aponta a Constituição Brasileira de 1988, a aprovação do Estatuto da Cidade e a criação do Ministério das Cidades como marcos de conciliação no processo histórico de desigualdade da sociedade brasileira. Tal relevância expõe a necessidade de discussão e 
reflexão do modo como tais instrumentos estão atualmente sendo conduzidos e como serão geridos pelos governo federal.

A concepção do Ministério das Cidades estabeleceu um fato inovador nas políticas urbanas no Brasil quando superou o recorte setorial da habitação, do ordenamento e planejamento territorial, do saneamento e dos transportes de modo a integrá-los considerando sobretudo a cidadania, o direito à cidade e a qualidade de vida. Ao refletir sobre sua extinção, questionase a continuidade do legado com a elaboração de diversas normas: as diretrizes gerais dos planos nacionais em vigência e as políticas urbanas para as próximas décadas, bem como o estabelecimento de metas específicas em cada município.

No período de sua atuação, o Ministério das Cidades proporcionou um momento pioneiro, pois, após a determinação do Estatuto da Cidade sobre a obrigatoriedade dos planos diretores bem como a utilização de instrumentos de política urbana e regularização fundiária, houve capacitação e treinamento das equipes técnicas responsáveis nas estruturas institucionais para elaboração e aprovação de tais planos, já que a sociedade civil e a gestão municipal também eram participantes ativos no processo.

Assim, o Estatuto da Cidade, no $\S 3^{\circ}$ do seu artigo 40, determina que, pelo menos, a cada dez anos, os planos diretores devem ser revistos conforme determinado na lei instituída pelo município. Após quase duas décadas de vigência do Estatuto, ressalta-se a relevância da análise dos planos diretores e suas respectivas revisões, sobretudo em cidades de porte médio, já que estas apresentam atualmente uma dinâmica de desenvolvimento diferenciadas das grandes cidades.

Entretanto, numa perspectiva em que a cronologia indicaria dedicação dos municípios para as primeiras revisões do plano diretor, na qual poder-se-ia resultar em relatórios, índices e parâmetros de como o Estatuto da Cidade previu a influência dos planos na garantia da função social da cidade e de como a aplicação de seus instrumentos atuaram na gestão do território dos municípios. Desta forma, vemos que a estrutura hierárquica da política urbana integrada está comprometida com a extinção do Ministério das Cidades.

\section{CONCLUSÕES}

Apesar de 30 anos de vigência da Constituição Federal, as decorrências desta sobre a política urbana no Brasil ainda são bastante inferiores ao potencial que o processo da reforma urbana pode alcançar. O momento da extinção do Ministério das Cidades deveria convergir para a análise das metas estipuladas pelo Estatuto da Cidade e coerente amadurecimento do modelo de governança urbana e participação popular, que ainda possuísse um caráter experimental. A expectativa das primeiras revisões dos planos diretores seria de aprimoramentos dos instrumentos e avaliação dos resultados físicos, territoriais ou socioespaciais. Entretanto, o cenário atual representa uma estagnação, podendo apresentar retrocessos nos avanços alcançados sobre a reforma urbana brasileira nas últimas décadas.

Após quase vinte anos de vigência do Estatuto da Cidade, ressalta-se a relevância da análise dos planos diretores e suas respectivas revisões de forma específica e individualizada em cada município buscando uma análise de resultados de avaliação do processo de avanço da política urbana.

\section{AGRADECIMENTOS}

O presente trabalho foi realizado com apoio da Coordenação de Aperfeiçoamento de Pessoal de Nível Superior - Brasil (CAPES) - Código de Financiamento 001.

\section{REFERÊNCIAS}

BELLON, Gabriel. Constituições estaduais pós-1989: o processo de emendamento e seus determinantes. 2016. Tese de Doutorado. Universidade de São Paulo. 
BONDUKI, Nabil. Dos movimentos sociais e da luta pela reforma urbana na Constituinte ao Estatuto da Cidade (1981-2001). In: BONDUKI, Nabil (Org.) A luta pela reforma urbana no Brasil: Do seminário de Habitação e Reforma Urbana ao Plano Diretor de São Paulo. São Paulo: Instituto Casa da Cidade, 2018.

BRASIL. Decreto $n^{\circ}$ 4.665, de 3 de abril de 2003. Aprova a Estrutura Regimental e o Quadro Demonstrativo dos Cargos em Comissão do Ministério das Cidades, e dá outras providências. Diário Oficial da União. Brasília, DF, 3 abr. 2003. Disponível em:

https://www.planalto.gov.br/ccivil_03/decreto/2003/D4665.htm. Acesso em: 17 mar. 2019.

BRASIL. Decreto $n^{\circ}$ 9.666, de 2 de janeiro de 2019. Aprova a Estrutura Regimental e o Quadro Demonstrativo dos Cargos em Comissão e das Funções de Confiança do Ministério do Desenvolvimento Regional, remaneja cargos em comissão e funções de confiança e substitui cargos em comissão do Grupo-Direção e Assessoramento Superiores - DAS por Funções Comissionadas do Poder Executivo - FCPE. Diário Oficial da União. Brasília, DF, 2 jan. 2019. Disponível em: https://www.planalto.gov.br/ccivil_03/_ato20192022/2019/decreto/d9666.htm. Acesso em: 18 mar. 2019.

BRASIL. Estatuto da Cidade - Lei n. 10257, de 10 de julho de 2001. Regulamenta os arts. 182 e 183 da Constituição Federal, estabelece diretrizes gerais da política urbana e dá outras providências. Diário Oficial da União. Brasília, DF, 10 jul. 2001. Disponível em: http://www.planalto.gov.br/ccivil_03/leis/leis_2001/l10257.htm. Acesso em: 18 mar. 2019.

CARDOSO, A. L. Reforma urbana e planos diretores: avaliação da experiência recente. Cadernos IPPUR, ano XI, n. 1; n. 2, Rio de Janeiro, p. 79-111, 1997.

DE GRAZIA, Grazia; RODRIGUES, Evaniza. UMA ALTERNATIVA PARA A GESTÃO URBANA: O MINISTÉRIO DAS CIDADES E SEUS DESAFIOS. Revista Rio de Janeiro, n. 9, p. 11-21, 2003.

MARICATO, Ermínia. Depoimentos. Pós. Revista do Programa de Pós-Graduação em Arquitetura e Urbanismo da FAUUSP, n. 14, p. 10-25, 2003.

SUTTI, Weber. O Ministério das Cidades e o ciclo de planos diretores do século XXI. In: BONDUKI, Nabil (Org.) A luta pela reforma urbana no Brasil: Do seminário de Habitação e Reforma Urbana ao Plano Diretor de São Paulo. São Paulo: Instituto Casa da Cidade, 2018. 